\title{
Empirical research on college student's role identity status in China
}

\author{
Zhou Yongkang ${ }^{1}$, Zeng Weixi ${ }^{2}$, Hu Yalin ${ }^{1}$, Wang Hui ${ }^{1}$ \\ ${ }^{1}$ School of Culture and Social Development Studies, Southwest University, Beibei Chongqing, China \\ ${ }^{2}$ School of Political Science and Public Administration, University of Electronic Science and Technology, Chengdu, Sichuan, China
}

\section{Email address:}

zyk@swu.edu.cn (Zhou Yongkang), zwx213@hotmail.com (Zeng Weixi), lindahuyalin@gmail.com (Hu Yalin), elain@swu.edu.cn (Wang Hui)

\section{To cite this article:}

Zhou Yongkang, Zeng Weixi, Hu Yalin, Wang Hui. Empirical Research on College Student's Role Identity Status in China. American Journal of Applied Psychology. Vol. 2, No. 6, 2013, pp. 94-100. doi: 10.11648/j.ajap.20130206.15

\begin{abstract}
College Student" is such a role that plenty of people once played, now are playing or will play in China. College students' positive identity of the role will help them develop well at this special stage. The definition of college students' role identity in the research is the cognitive orientation, emotive experience and behavioral reaction of college students to the student role they are playing. Based on the open-questionnaire investigation, the paper analyzed three status of college student's role identity by factor analysis technique: role adaptation, and role burnout and role contradiction. The paper also analyzed the difference on the three role identification status based on gender, birthplace, major, grade and other variables and the reason for the variance.
\end{abstract}

Key word: College Student, Role Identity, Role Adaptation, Role Burnout, Role Contradiction

\section{Introduction}

"College student" is a social role many Chinese people have once played or now are playing or will play. Since the late 1990s, the enrollment of universities and serious employment situation in China brought about a rapid devaluation to college student identity, from "a favored one by God" to "ordinary workers". These tremendous transformations and changes made people begin to re-examine the social role of "college student". More and more college students start to doubt themselves: "what does the role of college student mean to me?" "Why should I go to university?" Consequent confusions and perplexities has become a primary problem to a considerate part of college students. Positive identity to their roles as college students is beneficial to their healthy development in this stage of growth. With regard to this, it is necessary to study college student role identity structure.

Previous studies on college student role identity mostly follow self-identity study approach initiated by Erickson to Marcia's which highlights the individual point of view but less considers social factors (Erikson, Marcia, 1963, 1968, 1980, 2005 ). At present, a tendency of integration is appeared on the two approaches on identity, i.e. self-identity and social identity, which is that researchers began to analyze general self-identity problems in social role background (Kerpelman, Pittman, 1997; Dustin, Brent, 2006). Intergroup relationship defined by social role produces belongingness and self-worth in individuals, which makes people concentrate on who we are, and what we should do. In related studies from China, The Correlative Study on Self-identity Status and Personality Characteristic of College Student written by Guo Jinshan is more of an approach of self-identity, while Ethic Identity of Tibetan Undergraduates written by Wan Minggang and The Investigation on the Implicit Dimensions of Minority Undergraduates' Ethnic Identity in Southwest China written by Zhang Qinglin is more of an approach of social identity (Guo Jinshan, 2004; Wan Minggang, 2004; Zhang Qinglin, 2007). Since studies on college student's role identity are less perspected from the view of social identity of their student' s role, the paper tries to explore the role identity problem of college students from the perspective of social identity. Moreover, the authors are trying to establish a new research perspective of "self and social interaction" and integrate psychological approach with sociological approach in self-identity.

It is no doubt that practical and social significance exists on the research of college student's role identity. On one hand, it helps educators get more understanding of college 
students' role psychological development, thus motivating them to take appropriate action for their healthy development. On the other hand, Educators can get more perspectives from educational system, educational methods, educational policy, social environment and other social factors to understand college student's role identity issue, attracting attentions and reflection from relevant "significant others". Based on the consideration above, the research aims to: 1 . develop a structural questionnaire from which college student's role identity status could be judged; 2 . survey the role identity status of Chinese college studen and clarify its relationship with dependent variables.

\section{Method}

\subsection{Questionnaire}

Open questionnaire investigation and individual interview was conducted in 200 students in each grade from freshmen to senior, sampled 50 students each grade involved in arts, science, engineering, management and other discipline in Southwest University, Chongqing Normal University and Chongqing University. 178 valid questionnaires are collected with effective return-ratio at $89 \%$. Such following questions are included in the open questionnaire: (1) Do you identify with or accept the role of college student from the bottom of your heart, and why? (2) Do you think your situation is consist with the role of "college student" you are playing, and why? (3) Please talk about your college life specifically. Combined with individual interview materials, three sub-dimensions of college student's role identity were identified by content analysis for returned questionnaires.
After that, specific items of the questionnaire were developed with each item in the form of Likert five point scale, requiring subjects to answer each question as "totally disagree", "disagree", "uncertain", "agree", "totally agree" with corresponded score as 1, 2, 3, 4, 5. After developing the draft questionnaire, the researchers consulted and discussed with some experts and graduates to modify and refine, with worse item delelting and Exploratory Factor Analysis (EFA) adopting. Finally, a formal testing questionnaire about college student's role identity status with 21 items is developed.

\subsection{Formal Questionnaire Survey}

Formal questionnaire investigation with a total of 21 items was conducted to college students from Southwest University, Chongqing University of Post and Telecommunication, Chongqing Technology and Business University, Sichuan Normal University, China West Normal University, Southwest University of Science and Technology, Guangdong University of Technology, Hebei University of Science and Technology, Hangzhou Normal University and Tianjin University. 1956 questionnaires were collected out of 2318 copies randomly handed out with an effective return-ratio at $84.38 \%$. After excluding 95 questionnaires with incomplete personal basic information and incorrect answer to the question, 1861 valid questionnaires were obtained with effective rate as $80.14 \%$. SPSS13.0 was adopted for dealing with the survey datas.

\section{Results}

\subsection{Exploratory Factor Analysis}

Table 1. Exploratory factor analysis results of college student role identity status

\begin{tabular}{|c|c|c|}
\hline \multicolumn{3}{|c|}{ Role Adaptation (eigenvalue 11.61 , contribution rate $18.61 \%$ ) } \\
\hline Items & Factor loading & Common degree \\
\hline I take active part in my college life and study & 642 & .567 \\
\hline I know social expectations towards college students very well & .640 & .562 \\
\hline As a college students, I have a clear goal and plan for future & .570 & .481 \\
\hline I feel happy about my study and college life & .556 & .470 \\
\hline I try to develop my talents through various ways at university & .535 & .432 \\
\hline I am pleased to be a member of college students & .473 & .413 \\
\hline I firmly resist behaviors damaging the images of college students & .451 & .411 \\
\hline \multicolumn{3}{|l|}{ Role Burnout (eigenvalue 8.79 , contribution rate $11.15 \%$ ) } \\
\hline Items & Factor loading & Common degree \\
\hline I do not feel interested in anything at university & .575 & .493 \\
\hline I feel bored most of my time at university & .570 & .481 \\
\hline I have spent a large amount of time on recreation and entertainment & .531 & .417 \\
\hline I rarely put energy in professional learning and campus activities & .505 & .483 \\
\hline I often feel at loss in my college life & .496 & .486 \\
\hline College life means nothing to me & .481 & .467 \\
\hline Skipping classes is quite ordinary for me at university & .432 & .465 \\
\hline \multicolumn{3}{|l|}{ Role Contradiction (eigenvalue 4.12 , contribution rate $4.92 \%$ ) } \\
\hline Items & Factor loading & Common degree \\
\hline I advise people not to go to college & 670 & .499 \\
\hline I absolutely agree on the negative judgments on college students from society & 607 & .498 \\
\hline I have once thought about dropping out & .570 & .487 \\
\hline I do not care whether my behavior is identical with my college student identity & .537 & .445 \\
\hline I always show contempt of those who are proud of themselves as college students & .501 & .411 \\
\hline Going to college doesn't bring much benefits to me & .487 & .401 \\
\hline College life is extremely bored and oppressive & .456 & .397 \\
\hline
\end{tabular}


As shown in the table, exploratory factor analysis of formal questionnaires from open questionnaire and individual interview reveals three dimensions on role identity: role adaptation, role burnout and role contradiction, which totally explains $36.68 \%$ of total variance.

Role Adaptation is a positive role identity status, and college students in such a status have a clear cognition of their duties, goals and tasks, which they would describe as "I have a clear goal and plan for future". Also they feel proud, lucky, and happy about their "college student" identity, which they would describe as "I am pleased to be a member of college students". As well, they maintain, accept and adapt actively to their role identity, which they would describe as "I take active part in my college life and study", and "I firmly resist behaviors damaging the images of college students". Role adaptation shows a positive trendency on cognition, emotion and behavior.

Role Burnout is a neuter role identity status; college students in such a status may experience confusion, unawareness and numbness in role identity and behave negatively and loosely in role life. For example, "I do not feel interested in anything at university", "I often feel at a loss in my college life" and "I have spent a large amount of time on creation and entertainment".

Role Contradiction is a negative role identity. College students in such status depreciate self-role identity with a sense of strong role "stigma", thus they may have many negative feeling experiences and serious role contradiction behaviors in role life. For example, "I absolutely agree on the negative judgments on college in the society", "College life is extremely bored and oppressive", "I have once thought about dropping out" and "I advise people not to go to college".

\subsection{College Student's Role Identity Status}

\subsubsection{Overall Situation of College Student's Role Identity}

In order to investigate the overall situation of college student role identity, mean, standard deviation and coefficient of variation $(\mathrm{CV})$ on the above 3 different role identity status were statistically analyzed from 1861 college students participating in this study. Among them, the maximum point is 5 (full compliance), the minimum is 1 (totally inconsistent) and the critical value is 3 . Specific results are shown in Table 2.

Table 2. exploratory factor analysis of college student's role identity $(N=1861)$

\begin{tabular}{llll}
\hline & Mean & $\begin{array}{l}\text { Stardand } \\
\text { deviation }\end{array}$ & $\begin{array}{l}\text { Coefficient of } \\
\text { value(CV) }\end{array}$ \\
\hline Role adaptation & 3.48 & .55 & .16 \\
Role burnout & 2.77 & .66 & .24 \\
Role contradiction & 2.43 & .80 & .33 \\
\hline
\end{tabular}

As shown in the table, mean of "role adaptation" is 3.48, greater than the critical value 3 . That is to say, college students's evaluation of positive role identity is between "inconsistent" and "uncertain". Moreover, the coefficient of value is 0.16 , which demonstrates that students' positive identity is comparatively consistent. Means of "role burnout" and "role contradiction" are 2.77 and 2.43, both less than 3. That is to say, colleage students are "inconsistent" or"uncertain" with role burnout and role contradiction, which proved their positive role identity from the reverse. However, the $\mathrm{CV}$ of role burnout and role contradiction is 0.24 and 0.33 , both of which are greater, especially for"role contradiction".

\subsubsection{Detection Rates of Three Role Identity Status}

3 grades are devided by the means of 3 role identity status: means fewer than 2.5 are "not detected", those between 2.5 and 3.5 are "uncertain", and those greater than 3.5 are "detected". The detection rates on different dimensions of student's role identity are shown in Table 3.

Table 3. detection rate of three role identity status $(N=1861)$

\begin{tabular}{lllll}
\hline & & $\begin{array}{l}\text { Frenque } \\
\text { cy }\end{array}$ & $\begin{array}{l}\text { Percent } \\
(\%)\end{array}$ & $\begin{array}{l}\text { Cumulative } \\
\text { Percent (\%) }\end{array}$ \\
\hline $\begin{array}{llll}\text { Role } \\
\text { adaptation }\end{array}$ & uncertain & 1030 & 55.3 & 4.5 \\
& detected & 748 & 40.2 & 100.0 \\
& Not detcted & 607 & 32.6 & 32.6 \\
$\begin{array}{l}\text { Role } \\
\text { burnout }\end{array}$ & uncertain & 1005 & 54.0 & 86.6 \\
& detected & 249 & 13.4 & 100.0 \\
$\begin{array}{l}\text { Role } \\
\text { contradicti } \\
\text { on }\end{array}$ & Not detcted & 1159 & 62.3 & 62.3 \\
\hline
\end{tabular}

It is shown in Table 3 that $40.2 \%$ of the respondents demonstrate positive role identity---role adaptation, $13.4 \%$ demonstrate role burnout and $11.0 \%$ demonstrate role contradiction; while the majority (about 60\%) is in the intermediate state, in which they demonstrate neither higher positive identity, nor negative role identity.

\subsection{Related Factors Analysis of College Student's Role Identity Status}

\subsubsection{Gender Differences of College Student's Role Identity}

T-test results of independent samples of gender difference are shown in Table 4. On "role adaptation", boys' rating is significant higher than girls', which may indicates boys are more likely to demonstrate positive role identity tendency than girls. Although gender difference in "role burnout" and "role contradiction" is not significant, girls' grade evaluation is higher than boys', which may also show girls are more likely to demonstrate negative role identity. 
Table 4. Gender difference in college student's role identity ( $N=1861)$

\begin{tabular}{llllll}
\hline & Gender & Mean & SD & T value & P value \\
\hline Role & Male & 3.27 & 0.73 & $5.776^{* *}$ & 0.000 \\
adaptation & Female & 2.77 & 0.72 & & \\
& Male & 2.75 & 0.66 & -1.327 & 0.185 \\
Role burnout & Female & 2.79 & 0.68 & & \\
Role & Male & 2.40 & 0.81 & -1.311 & 0.190 \\
contradiction & Female & 2.45 & 0.80 & & \\
\hline
\end{tabular}

(*.05significant level, ${ }^{* *} .01$ significant level, the same below)

\subsubsection{Differences in Urban and Rural Background of College Student's Role Identity}

In Table 5, grade evaluation of urban students is significantly higher than that of rural students in "role adaptation", suggesting urban college students may be more aware of their role goals in college and has a positive role experience and active role behavior. While in "role burnout" and "role contradiction" factors, grade evaluation of rural students is higher than that of urban students, which perhaps shows that rural students are more likely to demonstrate negative role identity.

Table 5. Difference in urban and rural background of college student's role identity $(N=1861)$

\begin{tabular}{llllll}
\hline & $\begin{array}{l}\text { Urban or } \\
\text { rural }\end{array}$ & Mean & SD & T value & P value \\
\hline $\begin{array}{l}\text { Role } \\
\text { adaptation }\end{array}$ & Urban & 3.09 & 0.71 & & \\
& Rural & 2.72 & 0.74 & $2.209^{*}$ & 0.027 \\
Role burnout & Urban & 2.76 & 0.66 & & \\
& Rural & 2.79 & 0.68 & & 0.390 \\
Role & Urban & 2.42 & 0.81 & & \\
contradiction & Rural & 2.44 & 0.80 & & 0.532 \\
\hline
\end{tabular}

\subsubsection{Differences in Major of College Student's Role Identity}

Table 7. Main effect in grade analysis of college student role identity $(N=1861)$

\begin{tabular}{|c|c|c|c|c|c|c|}
\hline & Grade & Mean & SD & F value & P value & LSD \\
\hline \multirow{4}{*}{ Role adaptation } & Freshmen & 2.736 & .72 & \multirow{4}{*}{$8.585^{* *}$} & \multirow{4}{*}{0.000} & \multirow{12}{*}{$\begin{array}{l}\text { sophomore >freshmen }(*) \\
\text { sophomore }>\text { junior }(*) \\
\text { senior }>\text { freshmen }(*)\end{array}$} \\
\hline & Sophomore & 2.939 & .71 & & & \\
\hline & Junior & 2.837 & .73 & & & \\
\hline & Senior & 2.930 & .74 & & & \\
\hline \multirow{4}{*}{ Role burnout } & Freshmen & 2.797 & 0.69 & \multirow{4}{*}{.263} & \multirow{4}{*}{.852} & \\
\hline & Sophomore & 2.774 & 0.66 & & & \\
\hline & Junior & 2.768 & 0.65 & & & \\
\hline & Senior & 2.763 & 0.65 & & & \\
\hline \multirow{4}{*}{$\begin{array}{l}\text { Role } \\
\text { contradiction }\end{array}$} & Freshmen & 2.493 & 0.83 & \multirow{4}{*}{1.810} & \multirow{4}{*}{.143} & \\
\hline & Sophomore & 2.391 & 0.78 & & & \\
\hline & Junior & 2.431 & 0.78 & & & \\
\hline & Senior & 2.393 & 0.78 & & & \\
\hline
\end{tabular}

As is shown in table 6, difference in major is not significant. However, college students majoring in Science and Engineering has a higher rating in "role adaptation", a lower rating in "role burnout" and a slightly higher rating in "role contradiction" than those majoring in Arts.

Table 6. Differences in major of college student's role identity $(N=1861)$

\begin{tabular}{|c|c|c|c|c|c|}
\hline & Major & Mean & SD & T value & P value \\
\hline \multirow[b]{2}{*}{$\begin{array}{l}\text { Role } \\
\text { adaptation }\end{array}$} & Arts & 3.47 & 0.55 & \multirow[b]{2}{*}{-0.727} & \multirow[b]{2}{*}{0.467} \\
\hline & $\begin{array}{l}\text { Science and } \\
\text { engineering }\end{array}$ & 3.49 & 0.54 & & \\
\hline \multirow[b]{2}{*}{$\begin{array}{l}\text { Role } \\
\text { burnout }\end{array}$} & Arts & 2.78 & 0.66 & \multirow[b]{2}{*}{0.215} & \multirow[b]{2}{*}{0.830} \\
\hline & $\begin{array}{l}\text { Science and } \\
\text { engineering }\end{array}$ & 2.77 & 0.67 & & \\
\hline \multirow{2}{*}{$\begin{array}{l}\text { Role } \\
\text { contradiction }\end{array}$} & Arts & 2.42 & 0.79 & \multirow[b]{2}{*}{-0.573} & \multirow[b]{2}{*}{0.567} \\
\hline & $\begin{array}{l}\text { Science and } \\
\text { engineering }\end{array}$ & 2.44 & 0.80 & & \\
\hline
\end{tabular}

\subsubsection{Differences in Grade of College Student's Role Identity}

Results of one-way anova with "role adaptation", "role burnout" and "role contradiction" as dependent variable and grades as independent variable are shown in Table 7. Main effect of grade in "role adaptation" is significant and presents a stage change trend. It is found by post comparison (LSD) that grade evaluation of sophomore and senior in this factor is obviously higher than that of freshmen and junior. To put it in another way, positive role identity shows an upward trend during the period of freshmen and sophomore, and a downward trend during the period of sophomore and junior, and a regained upward trend during the period of junior and senior, presenting a trend of twists and turns. Grade main effects of "role burnout" and "role contradiction" are not significant. "Role burnout" presents a downward trend basically; while role contradiction shows a falling trend in sophomore, an increasing trend in junior and refalling trend in senior. 


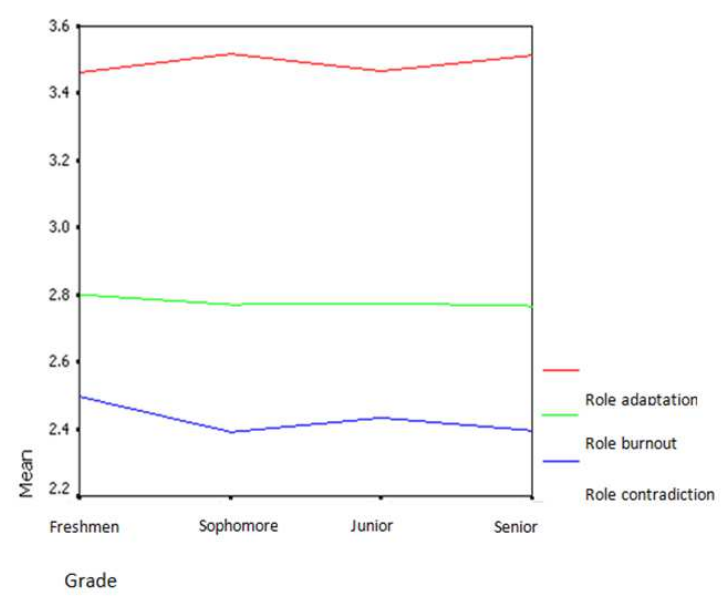

Figure 1. Grade change trend of colleage student's role identity

\section{Discussions}

\subsection{Internal Reason Analysis of College Student's Role Identity}

According to statistical results, although role identity crisis does not exist universally among college students in China, the overall situation is not satisfactory. For instance, role burnout ratio is up to $13.4 \%$ and role contradiction ratio is $11.0 \%$, presenting identity crisis is typical partially. Still, the $60 \%$ of intermediate students, who don't reach "role adaptation" status level, are negative role identity potentially.

Role confusion and perplexity of college students is caused by many reasons from college students themselves and society as well. From the perspective of colleage students themselves, the period from high school to university is an important stage in individual development, and also a stage of self-identity crisis proposed by Erikson. During this period, adolescents have to face many life issues, which may make them feel at loss and perplexed. At the same time, due to weak self-control or other individual reasons, many students may lose their way in self-indulgence from high school of heavy load to college of "easy study".

In contemporary China, employment is the most sensitive issue affecting college students in the four years' college study life. Confusion and perplexity for future goal and direction caused by employment pressure is the main problem troulbed the colleage students. Moreover, the employment problem is closely connected with college enrollment expansion in China and Chinese educational system. Firstly, in recent years, rapid college enrollment expansion suggested a symbol of the transformation of higher education from traditional elite education to mass education. However, for socio-cultural psychology inertia, it is hard for college students and their parents to accept the fact: "a favored one by God" has been depreciated to “ordinary workers", even so called "vunlerable group". In fact, for students, it is not the employment but the deep-rooted "elite consciousness" that matters, and this "elite consciousness" motivates them to find a more satisfactory job which can better reflect their "elite" identities. Therefore, the function of school education should narrow the gap between ideal role and actual role, transforming and updating content and training objectives from elite education to civic education so as to teach students to have civilian emotion, civilian ambition and qualities.

Secondly, Chinese educational system should undertake a considerable responsibility for the common role loss among contemporary college students. Exam-oriented education especially for college entrance examination has greatly damaged the overall development and role adaptation ability of Chinese juveniles. From primary school to high school, students are forced to repeatedly do exercises under the college entrance goal guided by parents, teachers and the society, and they are not supposed or expected to care about other things in their life. Before going to university, they have no idea about their future, their competence or hobbies, just being forced to learn, and then getting used to be forced. Once they go to colleage, a lot of them begin to frantically enjoy "freedom" like prisoners escaping from the prison; college becomes a compensation for repressed life in their adolescence. To some extent, role identity crisis and role loss among Chinese college students is an inevitable consequence of juvenile's long-term depression under exam-oriented education.

Moreover, there are a series of problems existing in Chinese higher education system and education pattern. Rigid administrative system has made higher education in China lack energy; partial pursuit of paper quantities and inapropriate assessment methods of research funds has helped to foster a climate of anxiety for quick success and instant benefit in college academic research; unsound supervision system has leaded to serious academic corruption. "Where are the great masters at university?" has become common question asked by many college students. In addition, majors and curriculums setup are not in line with market demand and "spoon-feed" teaching method still occupies the mainstream, which leads college students generally hold the opinion of "no use for learning" and "no strength for learning" and have no ability to deal with fierce job market competition. In brief, role identity is not only a personal psychological problem of college students, but also a social problem that requires reflection of the whole society.

\subsection{Cause Analysis of Gender Differences of College Student's Role Identity}

It is found in some related studies that there exists gender differences in college students' achievement motivation, presenting achievement motivation of male students is 
usually higher than that of female students. It is proved in many domestic and foreign researches that men are thought to be ambitious, independent spiritually, and competitive while women are thought to be dependent, tender and weak. Study of Banajihas proved that implicit gender stereotype that men will achieve greater success is widespread (Just, Banaji, 1994). Based on experimental dissociation paradigm, $\mathrm{Xu}$ Dazhen researched implicit gender stereotype and gender differences by adopting implicit and explicit measure means (Xu Dazhen, 2003). Accordingly, social affirmative evaluation to male college students is generally higher than that to female, which causes the lower role identity of female college students. In particularly, employment discrimination in the society results in a strong sense of frustration in female college students.

Althogh female college students don't show obvious identity to the gender role image set by Chinese traditional culture, most of them choose to let it be, actually showing a tendency of pursuing traditional feminization. A flourish advocation by the society of "the better half", "good wife and mother" and "wife back to life", misunderstandings and fear to successful women in real life and unfair employment competition facing female college students are all representations of the traditional notion in Chinese deep-rooted family ethnics that"dominating man and obedient woman" and "man out home, woman in". Social expectation towards women is under the constraint of traditional concepts to a great extent, and such expectation and comments have a direct impact on role identity of female college students.

\subsection{Cause Analysis of Urban-Rural Differences of College Student's Role Identity}

A research on Chinese rural college students reveals that when asked the question "Do you think you have already been a college student?". $11.17 \%$ of rural college students don't agree; $2.3 \%$ strongly disagree, with a total of $14 \%$ of subjects disagreeing with their college student role. $15.8 \%$ choose "I don't know", showing a blurry identity similar to the results showing in our research. (Lv Weihua, 2007). When a system-determined, man-made boundary continues to strengthen, it will have a stronger psychological effect on social members and lead to amplification to a certain identity value at the same time (Chen Yingfang, 2005). Urban-rural dualistic structural and institutional arrangements in China build up an insurmountable gap in people's social psychology. Negative and blurred identity of rural poor students is a result of loss of role identification mark in time-space transformation.

College students from rural areas are subject to greater expectations and responsibilities than urban students. With the big differences in wealth, social power and other social resources, the only hope for rural college students to enter the upper class is to receive equal education. However, rural students soon feel a sense of disillusion: a dilemma of "graduation means unemployment", an undoubtable fact that rising tuition makes many students from poor, closed and minority areas get a heavy debt at home before they finished studies. As a consequence, the role identity of college student has been a "useless" symbol to farmers and rural college students, thus the notion that "study is useless" reemerges in rural areas. Difficulty in employment of rural college students makes rural family once be prouded of college students suffer from psychological embarrassment and loss.

Meanwhile, rural college students experience the greatest confusion and stress due to the differences in value, lifestyle, knowledge structure and special hobbies resulted from urban-rural gap. Most college students from rural areas have a hard-working, introvert and strong-willed personality. Being the "excellent" in so many rural students, they are respected by many people and attract envious eyes in countryside. But once they are admitted to the university and set foot in the city, what they have heard and seen, as well as unique superiority of urban students, will change their original psychological atmosphere and increase the difficulty in role adaptation. Research also reveals that confusion and stress of rural college students in urban life results in their lower role identity than that of urban ones (Zhang Yiquan, Wang Yijie, 2006).

\subsection{Cause Analysis of Major Differences of College Student Role Identity}

There are many reasons resulting in higher positive identity of science and engineering students. Students majoring in science and engineering have more learning tasks and exercises every day, and their learning goal is relatively simple and specific compared to arts students, which makes science and engineering students feel less bored and more fulfilled. At the same time, science and engineering students generally are confronting with a better employment situation than arts students. As long as they have a solid and enough professional knowledge and skills, it is easier for science and engineering students to find a job. Thus, the goal they are tring to seek is clearer so that they present higher positive role identity. Conversely, learning goal and task of arts students is not that specific or simple compared to science and engineering students, coupled with severe employment situation, students majoring in arts feel that they lack professional skills and useful skills like science and engineering students. Grade evaluation in "role contradiction" of science and engineering students is slightly higher than that of arts students, the reason of which may be focused on learning issues. Science and engineering study requires a more solid foundation of mathematics and physics. Difficulty of these courses leads to study pressure among them. A study on learning burnout of college students shows that, emotion depression level, reduced accomplishment level and burnout level of science and engineering students are significantly higher than those of arts students, and the detection rate in high burnout in science and engineering students is higher than arts students (Niu Chunjuan, 2013). As a consequence, a part of 
science and engineering students may feel tired of study and even take confrontational role behavior due to learning stress. The results above indicate that polarization is more likely to occur among science and engineering students.

\subsection{Cause Analysis of Grade Differences of College Student Role Identity}

From the statistical results in this research, main effect of grade in "role adaptation" is significant and presents unique stage change trend: positive role identity shows an upward trend during the period of freshmen and sophomore, and a downward trend during the period of sophomore and junior, and a regained upward trend during the period of junior and senior. A possible explanation may be that, freshmen who just enter college from high school cherish a very idealistic expectation towards college life but only to discover reality is not the same thing as prior expectation. Coupled with differences in living environment, lifestyle and learning methods from those in high school, freshmen began to feel confused, perplexed and then have no sense of direction and purpose. With college life and learning continues, as well as their adaptation to the environment, college students gradually find the center of their own life and clear their objectives and directions after a year of exploration. So when sophomores being basically back to the right track, the second year is a relatively flat and busy time for them during their four years in college. Not only would college students in such stage work hard in studying, community activities, interpersonal relationships, love, cadres election of are also waving to them, which makes them feel fulfilled. Along with a deep exploration from their second year to the third year in college, confusion faced with college students is bound to increase, including problems of academic study, interpersonal relationships, love and other problems troubling them very much as well; in the meantime, what to do after graduation becomes an ineluctable problem, letting them suffer a new but different one with misery, confusion and perplexity from what they encounter in the first year in college. After a tough junior time, most of senior students have set up their own goals, such as taking part in postgraduate entrance examination, earning some certificates, finding a job or going abroad, with everything going step by step. At this time, there are less fickleness, depression, and madness, replaced by calmness in the face of future or a tranquil mentality even they feel confused. Above condition reminds us that psychological counseling for college student's role identity should be carried out not only after the enrollment at the university but also in the middle stage of university. Only by attaching much importance on physical and mental characteristics of college students of different gender, different family background, genders and grades, and developing good policy and carrying out effective psychological service system, can we help more and more college students develop positive role identity.

\section{References}

[1] Erikson, E. H. Childhood and society. New York: Norton, 1963

[2] Erikson, E. H. Identity: Youth and crisis. New York: Norton, 1968

[3] Marcia, J. E.Identity in adolescence. In J. Adelson (Ed.), Handbook of adolescent psychology. New York: John Wiley, $1980, \quad 159-187$

[4] Marcia. A. Finkelstein. Motive, Role Identity, and Prosocial Personality as predictors of volunteer activity. Social behavior and Personality, 2005, 33(4): 403-418

[5] Kerpelman, J.L., Pittman, J.F.Toward a microprocess perspective on adolescent identity development: An identity control theory approach. Journal of Adolescent Research, $1997,12: 325-346$

[6] Dustin Wood, Brent W. Roberts. Personality and Role Identity Structural Model. Journal of Personality, 2006, $74(6): 3$

[7] Perter J.Role theory and social cognition: learning to think like a recycler. Self and Identity, 2005, 4:45-58

[8] Guo Jinshan, Che Wenbo. The Correlative Study on Self-identity Status and Personality Characteristic of College Student [J].Psychological Development and Education, 2004 (2):51-55

[9] Wang Minggang, Wang Yapeng. Ethic Identity of Tibetan Undergraduates [J].Acta Psychologica Sinica, 2004, 36 (1) : $83-881$

[10] Zhang Qinglin. The Investigation on the Implicit Dimensions of Minority Undergraduates' Ethnic Identity in Southwest China [J]. Journal of Southwest University (Humanities and Social Sciences Edition), 2007(1):67-70

[11] Jost J.T.and M.R.Banaji.The Role of Stereotyping in System Justification and the Production of False Consciousness.British Journal of Social Psychology, 1994, 33:1-27.

[12] Xu Dazhen. The Effect of Gender on Gender Stereotypes [J]. Psychological Science, 2003(04)

[13] Lv Weihua. Social Identification and Social Construction of Poor College Students in Rural Areas [J].Youth Studies ,2007(1)

[14] Chen Yingfang. "Peasant-labor"System and Identity [J].Sociological Studies, 2005(3):119-132

[15] Zhang Yiquan, Wang Yijie. Research on life adaptation of rural college students [J]. Youth Studies, 2006(12):20-26

[16] Niu Chunjuan, Wu xuejiao, Chen Xiaomei, Zhang Lukun, Zhen Aowen, Correlation Analysis of Learning Burnout and Major Commitment of Colleage Students, China Power Education, 2013(7) 